\title{
The assessment of temperature and salinity sampling strategies in the Mediterranean Sea: idealized and real cases
}

\author{
F. Raicich \\ CNR, Istituto di Scienze Marine, viale Romolo Gessi 2, 34123 Trieste, Italy
}

Received: 20 March 2006 - Published in Ocean Sci. Discuss.: 16 May 2006

Revised: 1 August 2006 - Accepted: 17 August 2006 - Published: 30 August 2006

\begin{abstract}
Temperature and salinity sampling strategies are studied and compared by means of the Observing System Simulation Experiment technique in order to assess their usefulness for data assimilation in the framework of the Mediterranean Forecasting System. Their impact in a Mediterranean General Circulation Model is quantified in numerical twin experiments via bivariate data assimilation of temperature and salinity profiles in summer and winter conditions, using the optimal interpolation algorithm implemented in the System for Ocean Forecasting and Analysis. The data impact is quantified by the error reduction in the assimilation run relative to the free run.
\end{abstract}

The sampling strategies studied here include various combinations of temperature and salinity profiles collected along Volunteer Observing Ship (VOS) tracks, by Mediterranean Multi-sensor Moored Arrays (M3A), a Glider and ARGO floating profilers. Idealized sampling strategies involving VOS data allow to recognize the impact of individual tracks. As a result, the most effective tracks are those crossing regions characterized by high mesoscale variability and the presence of frontal structures between water masses.

Sampling strategies adopted in summer-autumn 2004 and winter 2005 are studied to assess the impact of VOS and ARGO data in real conditions. The combination of all available data allows to achieve up to $30 \%$ error reductions. ARGO data produce a small impact when alone, but represent the only continuous coverage of the basin and are useful as a complement to VOS data sets.

Localized data sets, as those obtained by M3As and the Glider, seem to have an almost negligible impact in the basinscale assessment, and are expected to be more effective at regional scale.

Correspondence to: F. Raicich

(fabio.raicich@ts.ismar.cnr.it)

\section{Introduction}

The Mediterranean Sea is a basin largely dominated by open ocean processes whose influence can be observed also in the coastal and shelf circulation. The large-scale general circulation is composed of intense coastal boundary currents and gyres with large seasonal and interannual variability (Malanotte-Rizzoli et al., 1999; Millot, 1999). The horizontal structure of the circulation is associated to vertical motions connected with the formation of deep and intermediate water masses. The major current structures and the watermass formation processes are driven by the atmospheric forcing, namely wind stress and heat fluxes.

The overall objective of the Mediterranean Forecasting System (MFS) is to explore, model and quantify the potential predictability of the marine ecosystem variability (Pinardi and Flemming, 1998). This task requires, among other elements, a suitable observational system to monitor the relevant physical and biogeochemical parameters. Different platforms contribute to the collection of temperature and salinity along the water column in the MFS. In particular, temperature is measured with eXpendable Bathy-Thermographs (XBTs) deployed along Volunteer Observing Ship (VOS) tracks, following the methodology described by Manzella et al. (2003); temperature and salinity profiles are measured by Conductivity-Temperature-Depth (CTD) probes included in Mediterranean Moored Multi-sensor Arrays (M3A) (Nittis et al., 2003, 2006 ${ }^{1}$ ), MedARGO profiling floats (Poulain, 2005) and by an autonomous Glider (http://www.ifm.uni-kiel.de). Such data are subsequently assimilated into a Mediterranean General Circulation Model (GCM) for the purpose of forecasting (Demirov et al., 2003).

\footnotetext{
${ }^{1}$ Nittis, K., Tziavos, C., Bozzano, R., Cardin, V., Thanos, I., Gačić, M., and Petihakis, G.: The M3A multi-sensor buoy network of the Mediterranean Sea, Ocean Sci. Discuss., submitted, 2006.
}

Published by Copernicus GmbH on behalf of the European Geosciences Union. 
The time and space coverage provided by oceanographic data sets is generally limited and the optimization of data sampling, although a desirable task, is in practice difficult to achieve due to financial and logistic constraints. The objective of the present work is to assess and compare the usefulness of a number of sampling strategies involving the collection of temperature and salinity profiles using Observing System Simulation Experiments (OSSE) techniques. The OSSE approach was first adopted by the meteorological community to assess the impact of future (i.e. not yet available from current instruments) observations, in order to improve numerical weather predictions, and to assess the design of observing systems and observing networks (e.g. Arnold and Dey, 1986; Rohaly and Krishnamurti, 1993). Previous oceanographic applications to sampling strategy optimization, or assessment towards optimization, are reported by Kindle (1986), Barth and Wunsch (1990), Bennett (1990), Hernandez et al. (1994) and Hackert et al. (1998). OSSEs were also recently applied to observing systems design assessment in the Atlantic Ocean, using statistical methods (Guinehut et al., 2002, 2004), in the Mediterranean Sea, using twin experiments (Raicich and Rampazzo, 2003; Griffa et al., 2006; Taillandier et al., 2006) and in the Baltic Sea and North Sea, in the Optimal Design of Observational Networks project (She et al., 2006).

The Mediterranean Forecasting System Pilot Project (MFSPP) experience was the first one in which OSSEs were applied to the Mediterranean Sea. Raicich and Rampazzo (2003) studied the impact on a Mediterranean GCM of sets of temperature profiles, obtained by XBTs deployed along VOS tracks and during aircraft surveys. The OSSEs used univariate assimilation of temperature data that allowed the explicit correction of temperature fields only, while the other prognostic variables changed as a consequence of that correction. The present work represents an evolution of the previous approach, consisting in the use of bivariate data assimilation of temperature and salinity profiles, thus enabling the explicit correction of both variables.

In the next section the methods will be outlined and in Sect. 3 the idealized and real sampling strategies studied in this work will be described. In Sects. 4 and 5 the results of the sampling strategy assessment will be summarized and discussed for the idealized and real cases, respectively. In Sect. 6 conclusive remarks will be presented.

\section{Methods}

\subsection{Twin experiments setup}

The OSSE technique used here consists of identical twin experiments, in which data extracted from a reference model run is assimilated into another run of the same model with different initial conditions. The convergence of the second run towards the first one is measured to quantify the data as- similation effectiveness in driving the model with "wrong" initial conditions towards the reference. Each twin experiment includes: a) a control run, which represents the "true" ocean and provides the simulated temperature and salinity data to be used in the assimilation; b) an assimilation run, with different initial conditions from the control run and including the assimilation of temperature and salinity data extracted from the control run; c) a free run, initialized as the assimilation run but without data assimilation. All runs are driven by the same external forcing.

The convergence of the assimilation run towards the control run is assessed by means of standard deviations of differences between the two runs (Miyakoda et al., 1969). The convergence of the free run towards the control run, assessed in the same way, is used as a reference, since it shows the ability of the model to converge towards the control run due to the external forcing. If, in a given spatial domain, we consider two n-dimensional samples of the assimilation run $\left(a_{i}\right.$, $\mathrm{i}=1, \ldots, \mathrm{n})$ and the control run $\left(c_{i}\right)$, let $m_{a}$ and $m_{c}$ be their arithmetic means over that domain and $a_{i}^{\prime}=a_{i}-m_{a}$ and $c_{i}^{\prime}=c_{i}-m_{c}$ the anomalies relative to those means. The relationship between the root-mean-squared difference $r m s$ and the standard deviation $\sigma$ is given by $r m s^{2}=r m s_{m}^{2}+\sigma^{2}$, where:

$$
\begin{aligned}
& r m s^{2}=\frac{1}{n} \sum_{i=1}^{n}\left(a_{i}-c_{i}\right)^{2}, \quad r m s_{m}^{2}=\left(m_{a}-m_{c}\right)^{2}, \\
& \sigma^{2}=\frac{1}{n} \sum_{i=1}^{n}\left(a^{\prime}{ }_{i}-c^{\prime}{ }_{i}\right)^{2}
\end{aligned}
$$

Thus, $r m s^{2}$ is the sum of a quantity $\left(r m s_{m}^{2}\right)$ depending on the means and one $\left(\sigma^{2}\right)$ depending on the anomalies. $\sigma$ is adopted instead of rms, since, as discussed in Raicich and Rampazzo (2003), it is more sensitive to data assimilation. Clearly, the same concept applies to the free run. In what follows the standard deviation will be denoted simply as the "error" and the ratio between the error in the assimilation run and the error in the free run as the "relative error".

The sampling strategy analysis is performed only for basin-scale regions, therefore standard deviations are computed for the western Mediterranean (Alboran Sea, Algerian Current region, Gulf of Lions, Tyrrhenian Sea and northern Sicily Channel) and eastern Mediterranean (southern Sicily Channel, Adriatic Sea, Ionian Sea, Aegean Sea and Levantine Basin) (Fig. 1). Three layers are taken into account, namely the surface layer (L1), consisting of 10 model levels from 5 to $240 \mathrm{~m}$ depth, the intermediate layer (L2), composed of 4 levels from 280 to $400 \mathrm{~m}$ and roughly corresponding to the Levantine Intermediate Water (LIW) layer (e.g. Malanotte-Rizzoli et al., 1999), and the deep layer (L3), which includes 17 levels from $440 \mathrm{~m}$ to the sea bottom.

The Mediterranean GCM used for the simulations is an eddy-resolving version of the Geophysical Fluid Dynamics Laboratory MOM-1 (Pacanowski et al., 1990), with $1 / 8^{\circ} \times 1 / 8^{\circ}$ grid mesh and 31 vertical levels $(5,15,30,50$, 
$70,90,120,160,200,240,280,320,360,400,440,480$, $520,580,660,775,925,1150,1450,1750,2050,2350$, 2650, 2950, 3250, 3550 and $3850 \mathrm{~m}$ ). Its implementation includes interactive surface heat flux calculation, surface salinity relaxation and constant vertical diffusion. Further details on the model and its setup can be found in Korres et al. (2000) and Demirov et al. (2003). The model is forced by ECMWF 6-hourly operational analyses, namely 10-m meridional and zonal wind components, 2-m air temperature, relative humidity and cloud cover. These variables are used interactively in the surface heat flux calculation. Precipitation and river runoff are not explicitly included, but implicitly taken into account, on average, by relaxing surface salinity to the MED6 climatology (Brasseur et al, 1996; Fichaut et al., 1998; Brankart and Pinardi, 2001). The model is capable to reproduce the major observed features of the circulation and water mass variability, as shown by Castellari et al. (1998, 2000) and Demirov and Pinardi (2002).

Data assimilation is performed by means of an optimal interpolation technique based on the scheme by Derber and Rosati (1989) and implemented in the System for Ocean Forecasting and Analysis (SOFA), described by De Mey (1994, 1997) and De Mey and Benkiran (2002). SOFA includes a reduced-order multivariate optimal interpolation scheme, where the order reduction is achieved by projecting the state vector onto vertical EOFs, that represent the eigenvectors of the error covariance matrix for the forecast. The scheme is multivariate in terms of both data input and corrections to the model output.

In the present work a model run is based on a sequence of two 7-day assimilation cycles, the first of which involving temperature and salinity (TS cycle) and the second sea-level anomaly (SLA cycle). In both cycles past and future observations within a 14-day window are included (smoother mode). In the TS cycle the assimilation of temperature and salinity profiles is performed by means of vertical bivariate EOFs estimated on regional and seasonal basis from a 1993-1999 GCM run. The technique used for the estimation and the region and season definitions are outlined by Sparnocchia et al. (2003). The first 20 EOFs are used, accounting for more than $99 \%$ variance. The choice of using a model run to estimate the EOFs is coherent with the fact that the OSSEs performed here involve GCM data instead of real observations. The better performance of assimilation with EOFs from model is shown in Fig. 2 for winter salinity in the western Mediterranean, in terms of relative errors, i.e. the ratios between the assimilation run error (sig_a in the figure) and the free run error (sig_f). This result holds also for temperature in the same region, while in the eastern basin the differences are smaller. SLA assimilation involves trivariate EOFs for the barotropic streamfunction, temperature and salinity. Only one trivariate EOF is used for the whole basin, extending from $120 \mathrm{~m}$ depth downward (Demirov et al., 2003) and the assimilation is made only in regions deeper than 1000 m (Özsöy et al., 1993). The choice of splitting TS and SLA assimilation is motivated by the fact that SLA is mainly affected by TS variability below the mixed layer, while CTD and XBT profiles provide water column properties also within the mixed layer. This splitting was adopted also by Demirov et al. (2003) in their "analysis" scheme, to which the scheme used in this work is similar.

Corrections are applied to the model temperature and salinity at the end of each TS cycle. The data error covariance radius is $10^{-6} \mathrm{~km}$ and the e-folding time is $10^{-6}$ days, implying that the data errors are uncorrelated with each other. The forecast error covariance radius is $45 \mathrm{~km}$ and e-folding time is 105 days, which results in giving all the data within the assimilation window essentially the same weight. The assimilation scheme and the parameter values are based on the model setup adopted by Demirov et al. (2003).

The SLA data assimilated every other cycle consists of weekly SLA analyses from real observations (LeTraon and Ogor, 1998) and has the purpose of providing the model with an external control. As anticipated in the Introduction, the twin experiments are performed to study the impact of temperature and salinity data, therefore the SLA data are the same in all runs.

OSSEs are made in two seasonal configurations defined as "summer" and "winter", according to the initial state of the ocean, and each experiment lasts for 70 days, corresponding to 10 assimilation cycles (5 TS cycles and 5 SLA cycles). In the summer OSSEs the control run is initialized on 1 September 1999, with end on 9 November 1999, while in the winter OSSEs the control run covers the period 1 February-10 April 2000. Free run and assimilation run are initialized on 1 September 1998 (summer) and 1 February 1999 (winter), that is exactly one year before the control runs. The initial conditions for all the above-mentioned runs are taken from an interannual simulation performed with assimilation of XBT and SST heat flux correction (Demirov et al., 2003), forced by ECMWF 6-hourly reanalyses.

\subsection{From univariate to bivariate data assimilation}

The application of multivariate data assimilation enables to overcome a limitation that affected the sampling strategy assessment performed in the MFSPP (Raicich and Rampazzo, 2003), where only univariate temperature assimilation was available. Figure 3 displays a comparison of daily winter salinity relative errors for the whole Mediterranean Sea obtained in runs with univariate temperature assimilation (UT), bivariate temperature assimilation (BT) and bivariate temperature and salinity assimilation (BTS). For this comparison the assimilation setup is different from that described in Sect. 2.1: a) The data set consists of profiles along all the VOS tracks of the network adopted during the MFSPP, extensively described in Raicich and Rampazzo (2003); b) data assimilation involves $\mathrm{T}$ and $\mathrm{S}$ only and is performed with a 7-day cycle using only past data (filter mode). In the UT run salinity changes are the result of the model rearrangement 


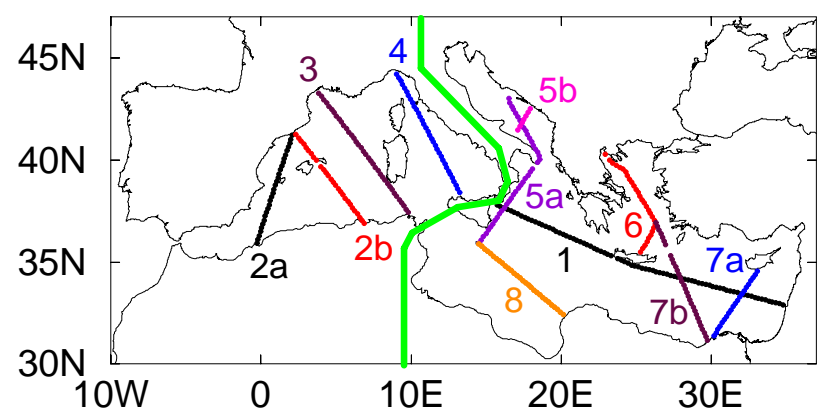

Fig. 1. Design of the VOS track network. The green line separates western and eastern Mediterranean.

induced by temperature correction. In the BT run temperature is still the only observable available for assimilation, but salinity is also assimilated, after being estimated by means of the vertical EOFs, and corrected. Finally, in the BTS run both temperature and salinity are explicitly assimilated and corrected. From Fig. 3 it is evident that BTS performs much better than UT and BT (that are similar) in both L1 and L2, with a relative error reduction of about $20 \%$. In L3 (not shown) the relative error reductions for UT and BTS are similar and both less than $10 \%$, while BT does not exhibit any improvements over the free run. The latter fact may be due to an inadequate EOF estimate of salinity, which is statistical and may not represent well the water column conditions of the specific time when the experiment is performed. The same analysis for temperature shows that, although the relative error reductions in the three runs do not differ much from each other, temperature benefits from the explicit assimilation of salinity, particularly in the western basin.

\section{Sampling strategies description}

In this work two types of sampling strategies are studied, namely idealized and real. Idealized sampling strategies are those with a realistic basis but that cannot be adopted because the sampling is either too frequent in time or too dense in space than practically achievable, or because observations are not really performed although potentially feasible. Their study is essentially made for a comparative assessment of different elements of the observing system. Real sampling strategies involve actual data distributions and enable the assessment of the whole observing system or parts of it.

Among the idealized sampling strategies this work examines those involving profiles obtained from the deployment of probes along VOS tracks and from CTD measurements at M3A sites. At present only temperature profiles are measured along VOS tracks using XBTs. In order to obtain also salinity, XCTDs (eXpendable CTDs) would be required, but they are not available. In the OSSEs the case of both temperature and salinity profiles from VOS will be studied. In

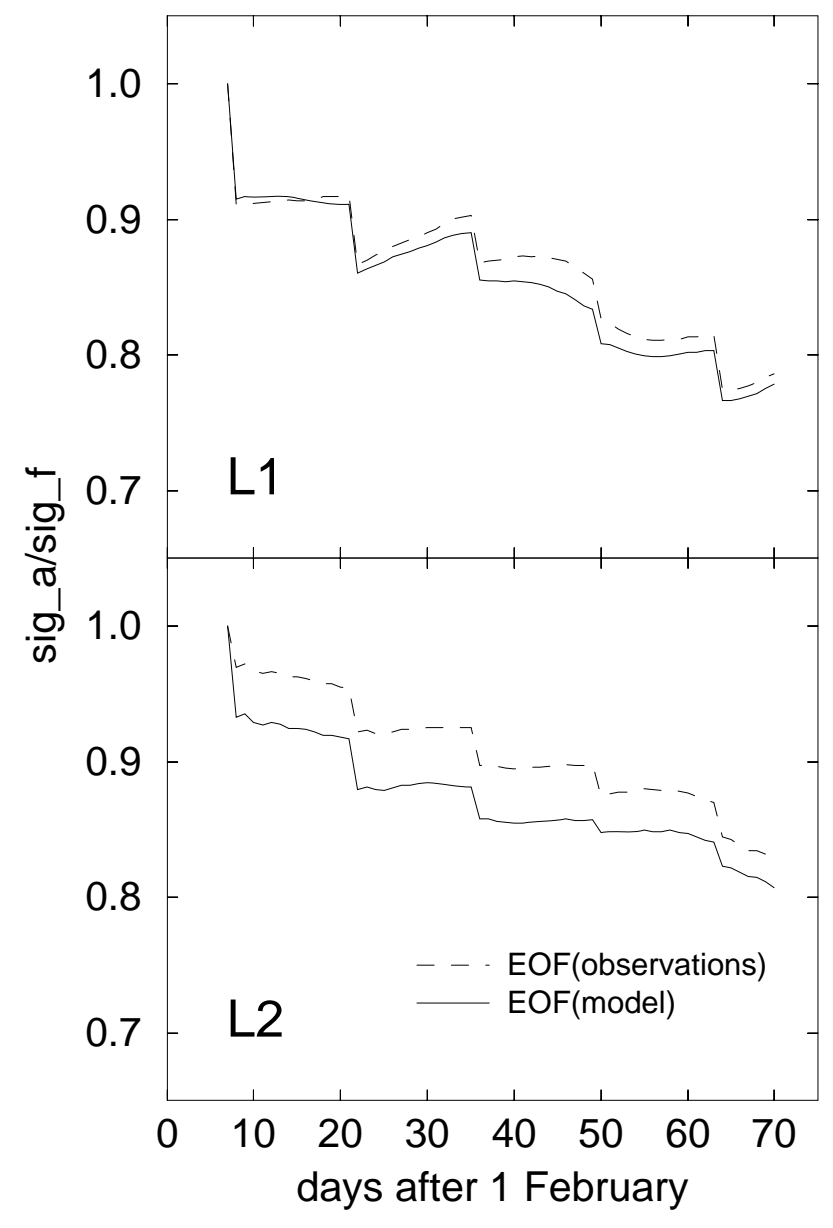

Fig. 2. Time series of winter salinity relative errors with bivariate temperature and salinity assimilation using EOFs from observations and from GCM 1993-1999 interannual run.

this work the elements of real data distributions are the VOS track network design and the time availability of typical M3A data, while the other details described below are idealized, although realistic. The idealized sampling strategies under study are:

1) IdVOS (Idealized VOS): The spatial design is based on the scheme of track network adopted in the VOS programme of the Mediterranean ocean Forecasting System Towards Environmental Predictions (MFSTEP) project (Manzella et al., 2003), shown in Fig. 1. The time coverage adopted in the numerical experiments is regular and more frequent than in practice. It is assumed that XCTD probes are released from VOS every 12 nautical miles, the times of deployment being computed on the basis of nominal VOS speeds. For each track the numbers of profiles are: 82 (track 1), 57 (track $2=2 a+2 b), 41$ (track 3), 35 (track 4), 51 (track $5=5 a+5 b), 30$ (track 6), 54 (track $7=7 a+7 b)$ and 60 (track 8). All tracks are covered once a week except 
Table 1. Positions of the M3As considered in this study.

\begin{tabular}{cccccc}
\hline \multicolumn{2}{c}{ Western Mediterranean } & \multicolumn{3}{c}{ Eastern Mediterranean } \\
Array & Latitude N & Longitude E & Array & Latitude N & Longitude E \\
\hline W1 & 43.79 & 9.16 & E1 & 35.73 & 24.92 \\
W2 & 42.00 & 4.00 & E2 & 41.28 & 17.66 \\
W3 & 39.00 & 6.00 & E3 & 35.50 & 15.50 \\
W4 & 36.00 & -5.00 & E4 & 35.50 & 21.50 \\
W5 & 37.00 & -1.00 & E5 & 34.50 & 28.50 \\
W6 & 38.00 & 11.00 & E6 & 33.50 & 33.50 \\
W7 & 39.00 & 12.50 & E7 & 37.50 & 16.00 \\
& & & E8 & 39.00 & 25.50 \\
& & & E9 & 33.00 & 28.50 \\
\hline
\end{tabular}

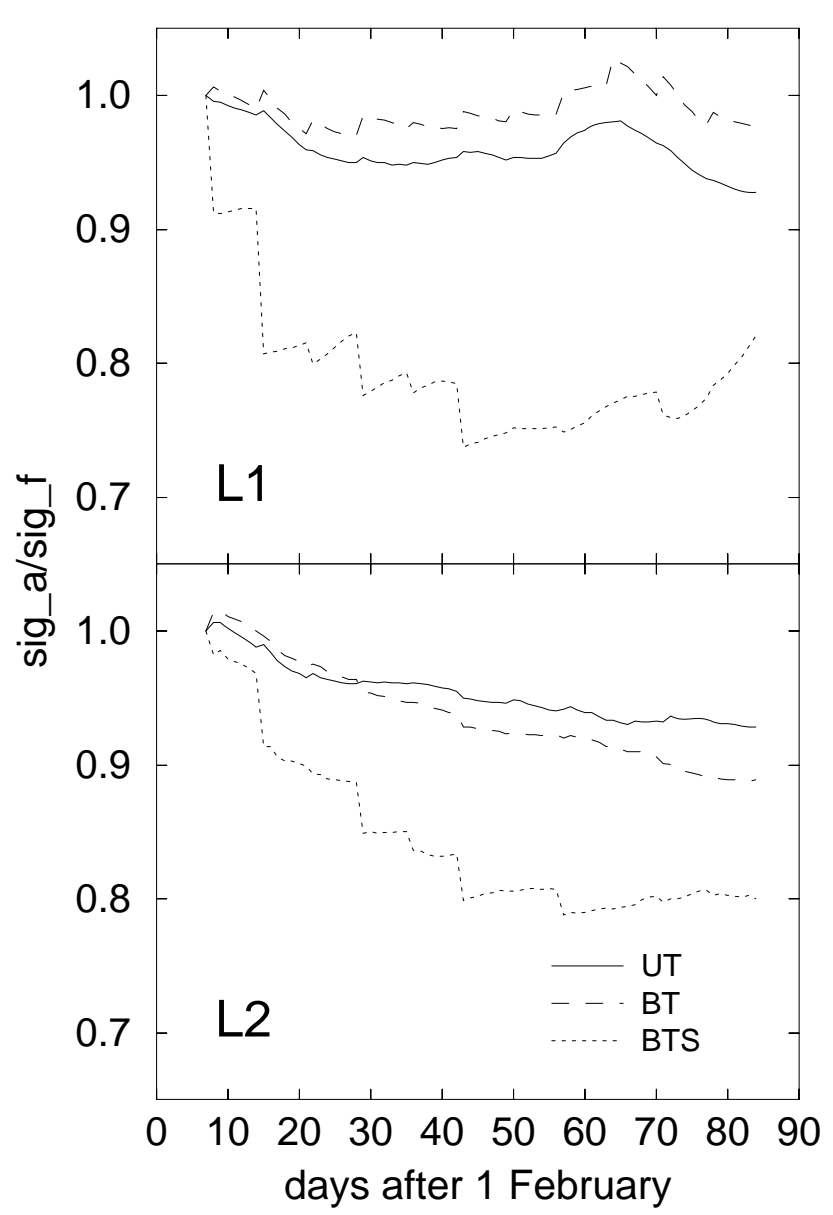

Fig. 3. Time series of winter salinity relative errors for the whole Mediterranean Sea with univariate temperature assimilation (UT), bivariate temperature assimilation (BT) and bivariate temperature and salinity assimilation (BTS). L1 indicates the surface layer and $\mathrm{L} 2$ the intermediate layer.

tracks $2 \mathrm{a}$ and $7 \mathrm{a}$, only in the odd weeks, and $2 \mathrm{~b}$ and $7 b$, only in the even weeks. The maximum depth of the synthetic profiles is $775 \mathrm{~m}$ (model level 20).

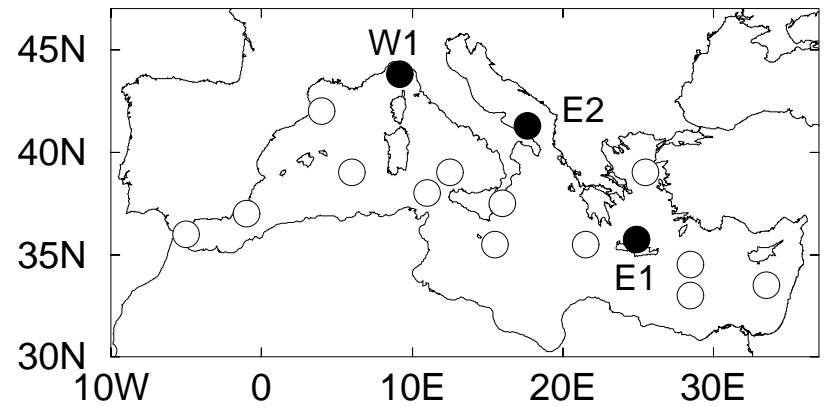

Fig. 4. The M3A network. Black circles represent buoys active in MFSTEP, white circles represent a possible development of the network.

2) IdVOS-n (with $n$ varying from 1 to 8 ): These sampling strategies are identical to IdVOS except that track $n$ is not included.

3) IdM3A (Idealized M3A): The simulated M3A network consists of the sites that are active in MFSTEP (W1, E1 and E2) as well as those that might be included as possible future developments of the MFS according to the science plan (Pinardi and Flemming, 1998; Nittis et al., 2003) (Fig. 4). The positions of the $16 \mathrm{M} 3 \mathrm{As}$ are listed in Table 1. The active M3As exhibit different instrumental arrangements and temperature and salinity data are measured at different depths. However, for simplicity, the M3As used in this impact study are all assumed to be equal to the array moored in the southern Aegean Sea off Iraklion, on the Northern coast of Crete Island. At this M3A site, temperature and salinity are measured at 1.5, 30, 50, 75, 100, 150, 250, 350 and $500 \mathrm{~m}$ depth (Nittis et al., 2006 ${ }^{1}$ ). These depths approximately correspond to the following Mediterranean GCM levels: $5 \mathrm{~m}$ (level 1), 30 (3), 50 (4), 70 (5), 100 (6), 160 (8), 240 (10), 360 (13) and $480 \mathrm{~m}$ (16). The real M3A acquires data every hour and transmits them 


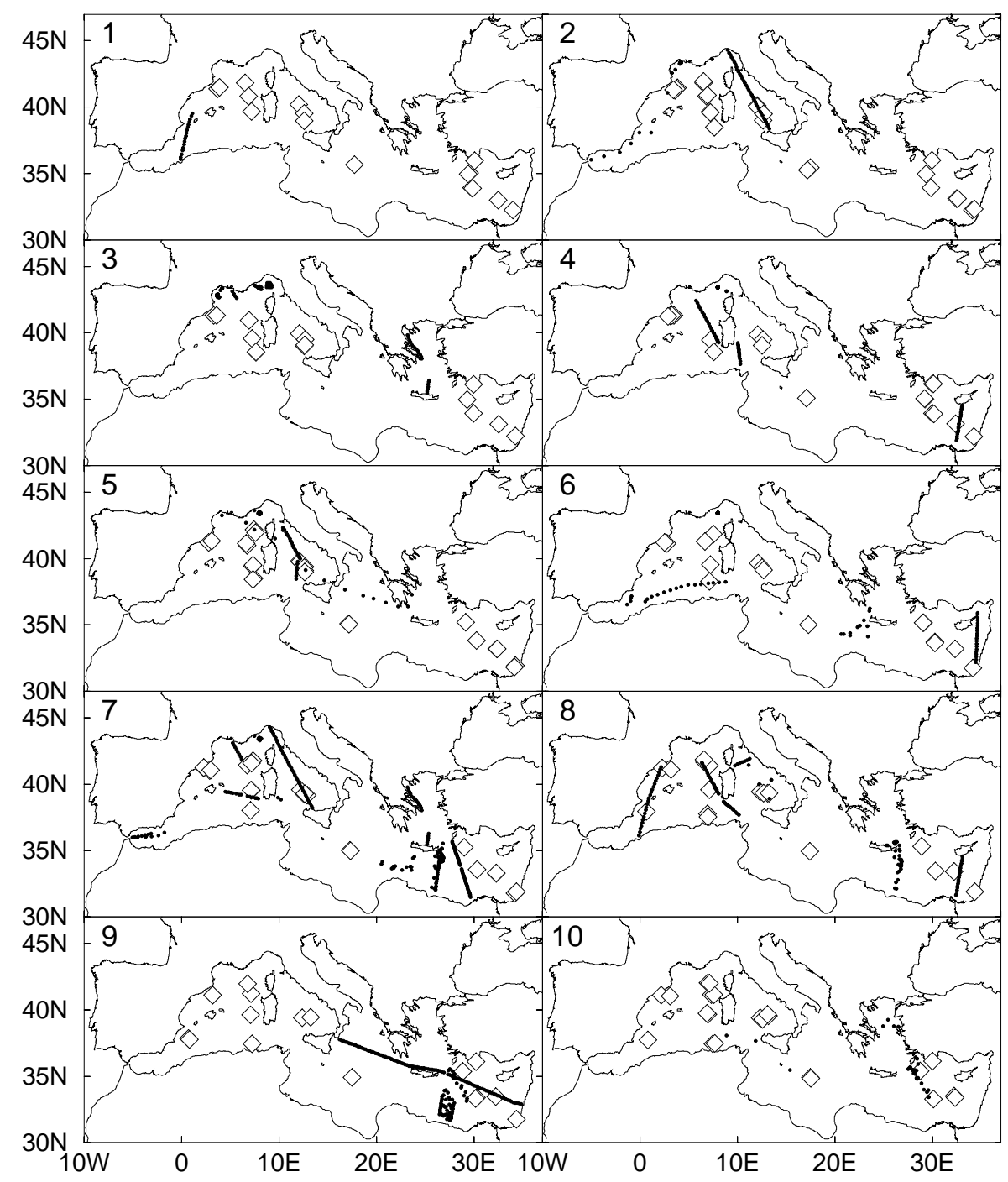

Fig. 5. Weekly spatial distributions of profiles collected along VOS tracks and from other ships (black dots) and from ARGO floats (white diamonds) in the Mediterranean Sea from 1 September to 9 November 2004. The week number is shown in the top left corner of each panel.

every $3 \mathrm{~h}$. The simulated data are provided every $6 \mathrm{~h}$, namely at 00:00, 06:00, 12:00 and 18:00 UTC.

4) IdVOSM3A: The combination of IdVOS and IdM3A.

The real sampling strategies studied in this work are defined on the basis of the observations that have been performed in the Mediterranean Sea in 2004 and 2005, mostly during the MFSTEP Targeted Operational Period. The following real sampling strategies are taken into account:

1) Vt (real VOS): Temperature profiles obtained from XBTs deployed along MFSTEP VOS tracks and from other ships.

2) ARGO (real ARGO): Temperature and salinity profiles from ARGO floats used in MFSTEP (MedARGO) and other programmes.
3) VtARGO: The merging of Vt and ARGO.

4) VtARGOG: The merging of VtARGO and Glider data, only in the East Mediterranean. In the group of real sampling strategies two other cases are considered, in which salinity profiles, that are not actually available, are added to the real VOS temperature profiles, thus simulating the deployment of XCTDs:

5) Vts: Temperature and salinity profiles obtained along MFSTEP VOS tracks and from other ships.

6) VtsARGO: The merging of Vts and ARGO.

Figures 5 and 6 show the VOS and ARGO data positions during the ten weeks of the summer (1 September-9 November 2004) and winter (1 February-10 April 2005) OSSEs, respectively. All the Glider data positions are shown together 


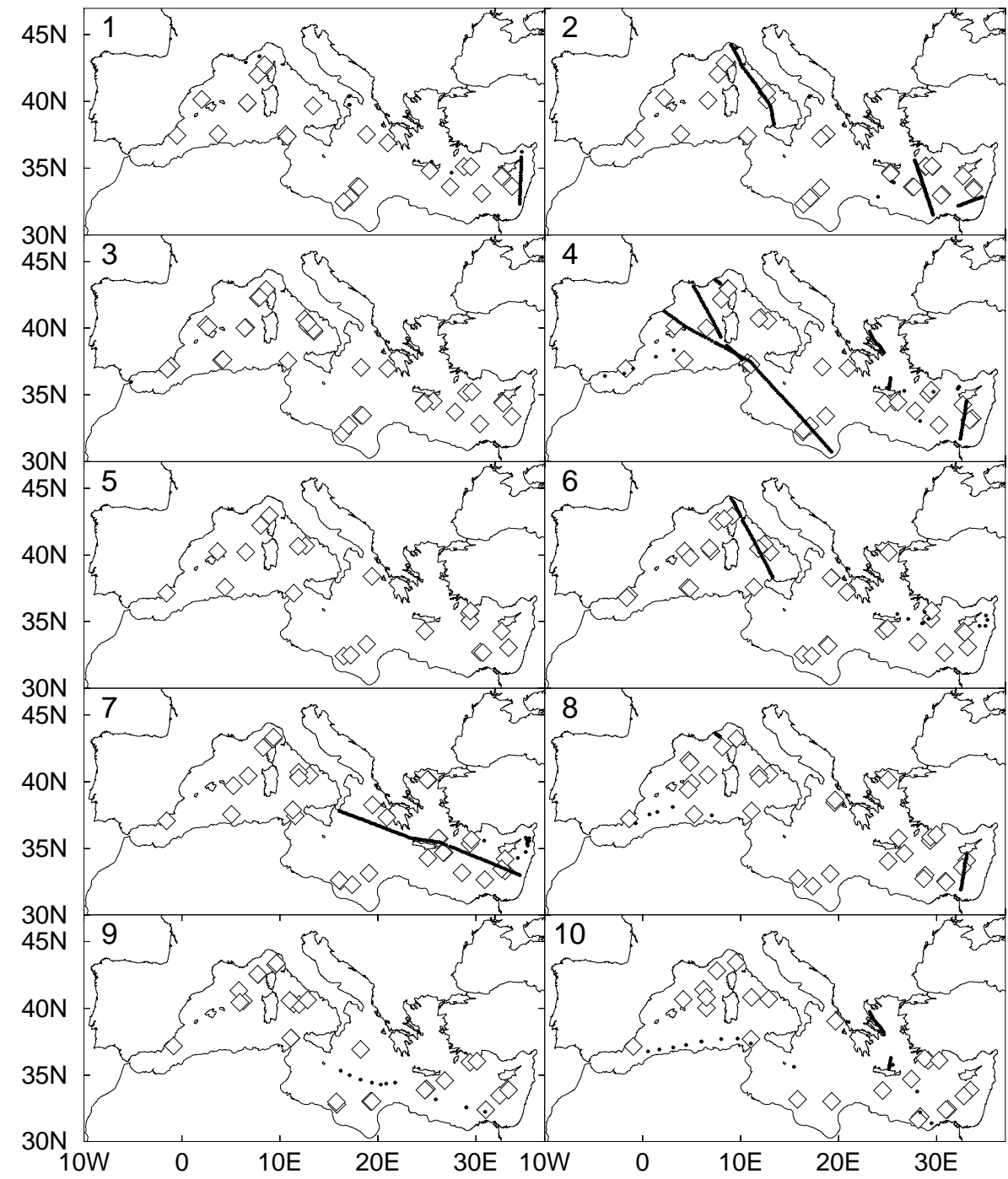

Fig. 6. As Fig. 5 for the data from 1 February to 10 April 2005.

in Fig. 7. Table 2 summarizes the number of profiles available weekly for each sampling strategy and the Glider. The maximum depth of VOS profiles is $775 \mathrm{~m}$ (model level 20), that of ARGO profiles is $660 \mathrm{~m}$ (model level 19) and that of Glider profiles is $925 \mathrm{~m}$ (model level 21). It should be stressed that, even when the sampling strategies are based on real data distributions, only the data times and positions are taken from the survey schemes, while the temperature profiles for assimilation are always extracted from the control runs, namely for summer-autumn 1999 and winter 2000, at the appropriate times and positions. Summer and winter OSSEs are performed for all the sampling strategies described above.

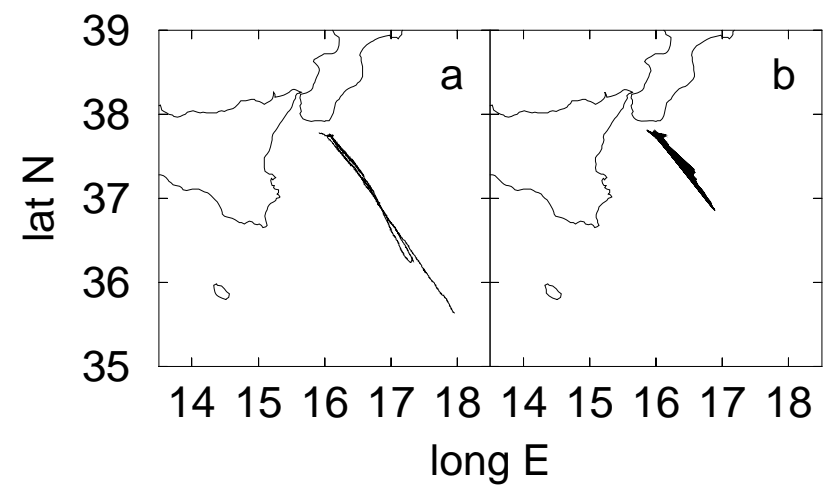

Fig. 7. Spatial distributions of Glider profiles in the periods 1 September-9 November 2004 (a) and 1 February-10 April 2005 (b). 
Table 2. Number of profiles available weekly for each sampling strategy and the Glider in the western (W) and eastern (E) Mediterranean.

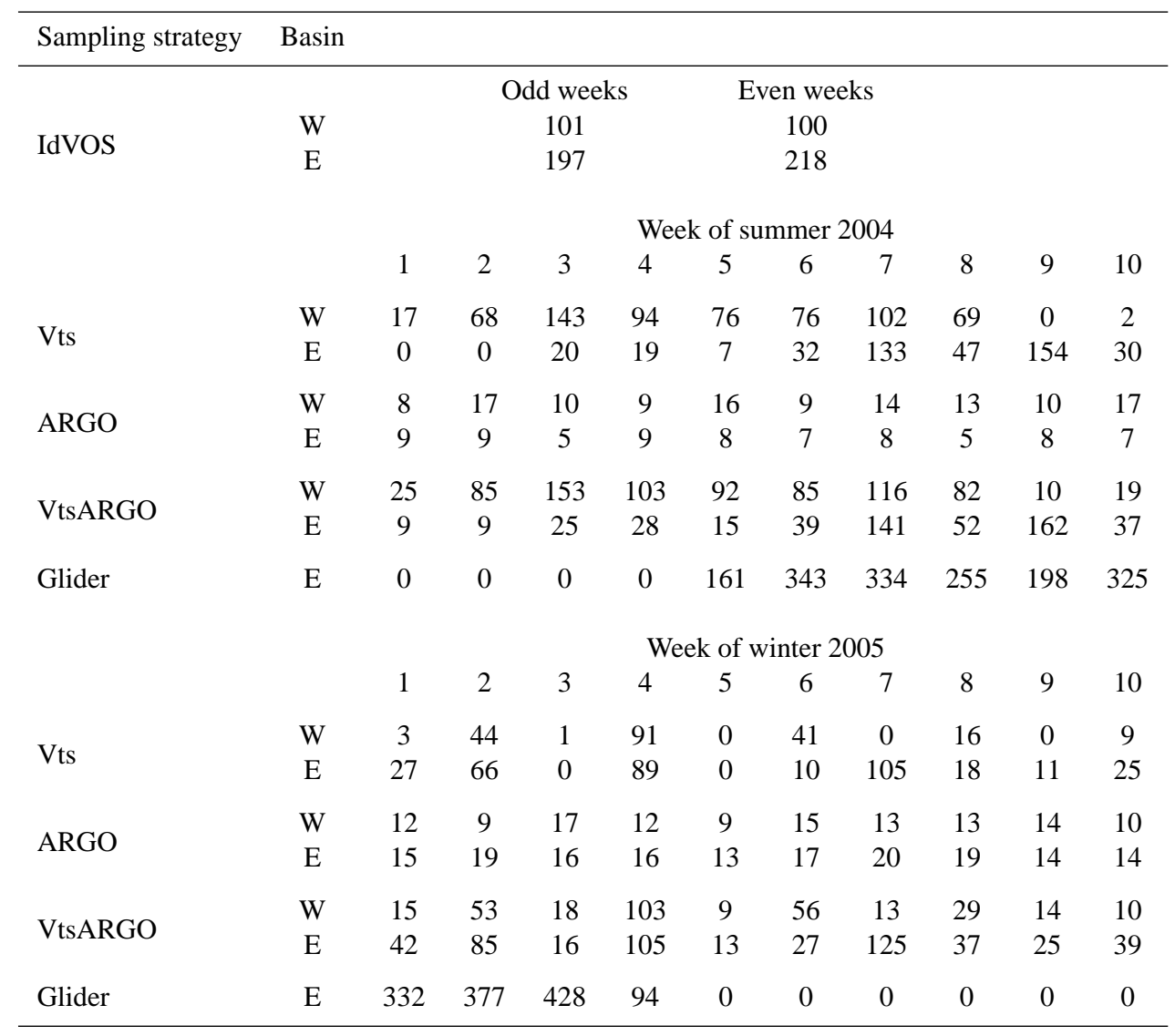

\section{Assessment of idealized sampling strategies}

Figures 8-9 display examples of temperature and salinity relative errors computed on a daily basis for the idealized sampling strategies involving only VOS profiles, that are outlined in Sect. 3. The comparison of sampling strategies IdVOS-n $(n=1, \ldots, 8)$ with the basic strategy IdVOS allows to estimate the amount of relative error reduction lost by removing track $\mathrm{n}$, and, therefore, the relative impact of that track. Note that, for a given Mediterranean subbasin (western or eastern), the comparison involves only the tracks crossing that subbasin, namely tracks 2, 3, 4 for the western Mediterranean and tracks 1, 5, 6, 7, 8 for the eastern Mediterranean. The reason is that, within the experiment duration, the impact of each track is negligible in the other subbasin.

In the summer OSSEs in the western basin (Fig. 8a) the relative error reduction achieved in L1 by strategy IdVOS reaches $20 \%, 10-15 \%$ for temperature and up to about $20 \%$ for salinity, at the end of the experiment, in L2, and less than 5\% in L3, i.e. almost negligible. The curves for strategy IdVOS-2 approach 1 and are clearly distinguishable from the others. This means that track 2 has a strong impact on data assimilation, since its removal leads to almost no improve- ment over the free run. By contrast, the impact of track 4 is small, as shown by the very small differences between the IdVOS- 4 and IdVOS curves. The removal of track 3 produces a little improvement in L2 and L3, more marked for temperature (not shown), probably because the assimilation of data along track 3 produces an undesired correction to the model in some areas. This fact can occur since the correction, whose magnitude depends on the difference between assimilation and free runs, is propagated away from the data positions. It may then affect area where the difference between assimilation and free runs is much smaller or even of opposite sign, and, therefore, does not require that correction. This situation may be expected particularly in case of high mesoscale variability. A more adequate choice of the forecast error covariance radius, for instance spatially variable, can probably reduce this problem.

In the eastern Mediterranean (Fig. 8b) the situation is more complex. Strategy IdVOS leads to a maximum error reduction of about $15 \%$ for temperature and $10 \%$ for salinity in $\mathrm{L} 1,20 \%$ in $\mathrm{L} 2$ and about $15 \%$ in L3. A remarkable result is represented by the large impact of track $5(5 a+5 b)$ in L2 and L3, both for temperature and salinity, with error reduction loss of $10-15 \%$ relative to strategy IdVOS. In L1 track 


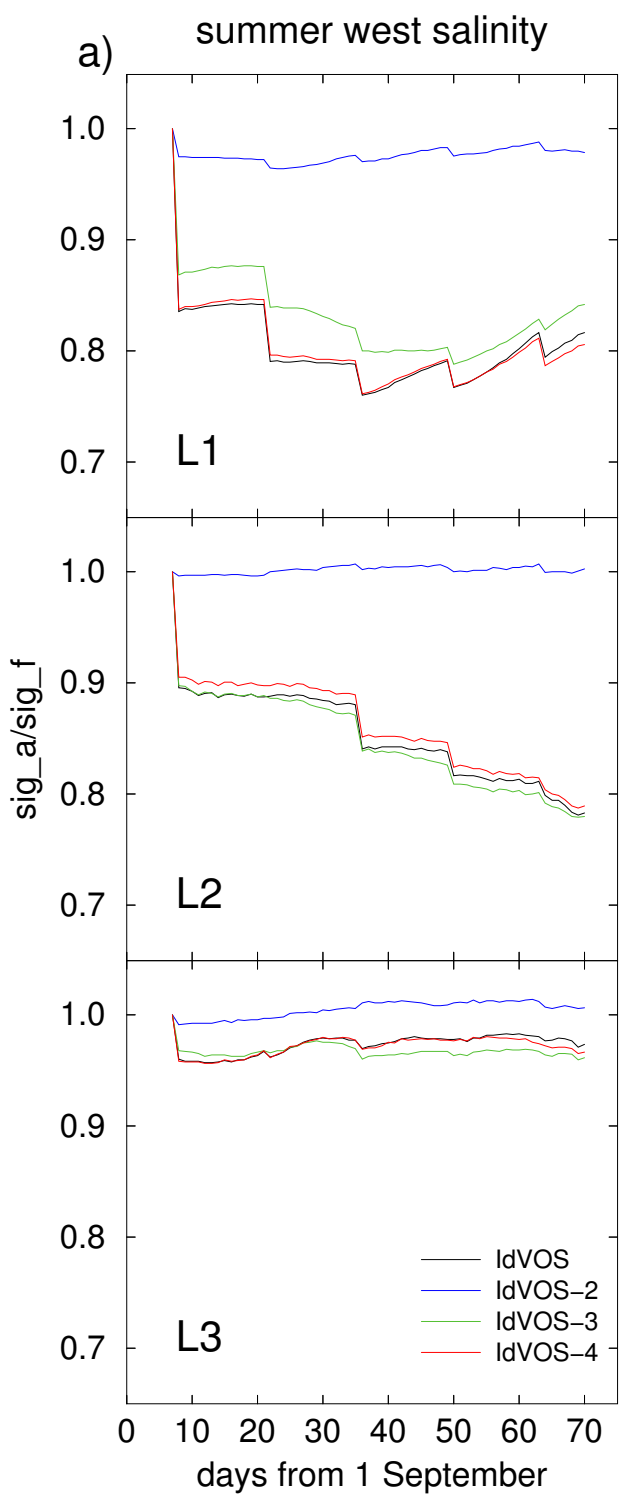

b) summer east temperature

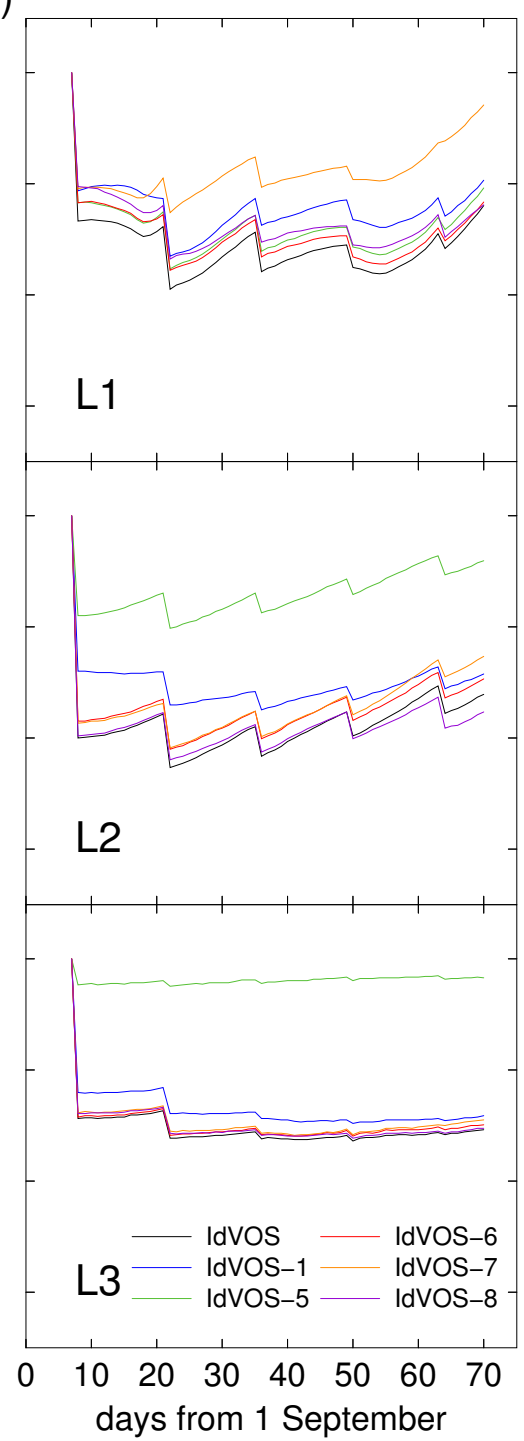

Fig. 8. Time series of relative errors in the summer OSSEs for idealized samplings of VOS data: (a) West Mediterranean salinity, (b) East Mediterranean temperature. L1 indicates the surface layer, L2 the intermediate layer and L3 the deep layer.

$7(7 a+7 b)$ seems important for temperature only. Despite its length, track 1 has a comparatively small impact.

The importance of track 2 in the western Mediterranean is observed also in winter (Fig. 9a). Temperature and salinity relative error reductions achieved by strategy IdVOS reach $20-30 \%$ in L1 and L2 and 10-15\% in L3, while with IdVOS2 they drop to approximately 5\%, except for temperature in L2 with $10 \%$ (not shown). In the eastern basin (Fig. 9b) strategy IdVOS leads, at the end of the run, to maximum relative error reductions of about $20 \%$ for temperature and $15 \%$ for salinity in L1 and L2, and less than $10 \%$ in L3. In general, all the sampling strategies exhibit similar impacts, with the only exception found for temperature in L2, where the relative error reduction with strategy IdVOS-1 appears to be relatively small during most of the run, however converging towards that of the other strategies. As in summer, the absence of track 7 has a certain effect in $\mathrm{L} 1$ for temperature. The impact of track 5 is less marked than in summer, since only salinity exhibits an error reduction loss of about $5 \%$ in all layers (not shown).

Although it is reasonable to relate the impact of a track mainly to its length, which determines the area where the model is corrected by data assimilation, tracks crossing regions with complex dynamics produce a stronger impact. The Mediterranean Sea circulation is highly variable both in space and time, due to the presence of gyres, currents and frontal structures that exhibit notable interannual variability (Malanotte-Rizzoli, 1999; Millot, 1999). Figure 10 displays 

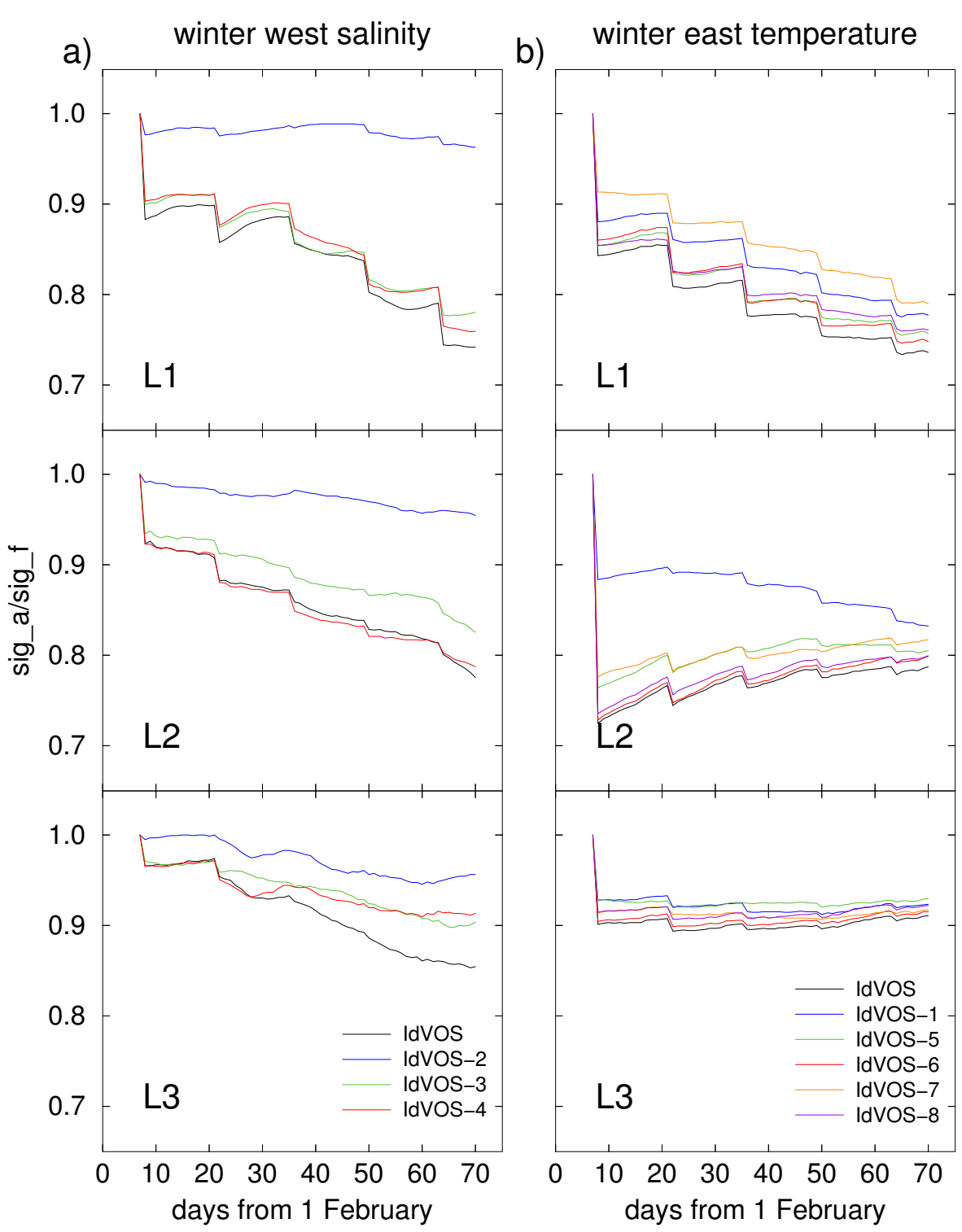

Fig. 9. Time series of relative errors in the winter OSSEs for idealized samplings of VOS data: (a) West Mediterranean salinity, (b) East Mediterranean temperature. L1 indicates the surface layer, L2 the intermediate layer and L3 the deep layer.

the differences between the initial conditions of the assimilation and the control runs for summer salinity at $320 \mathrm{~m}$ depth and winter temperature at $70 \mathrm{~m}$. Changes at the mesoscale are generally observed, but also larger scale differences are evident. For instance, in summer at $320 \mathrm{~m}$ depth (Fig. 10a) the assimilation run starts with lower salinity than the control in the northern part of the East Mediterranean, while salinity is higher close to the Gibraltar Strait. In winter at $70 \mathrm{~m}$ depth (Fig. 10b) at the beginning of the assimilation run temperature is generally lower than in the control in the southern part of the eastern basin, whereas it is higher in the northern and eastern Levantine Basin and part of the West Mediterranean. From the numerical experiments it turns out that, in order to better drive the model towards the truth in the as- similation run, the observations performed in areas with high spatial variability can be critical. Relatively large differences between the assimilation and free runs are more likely to occur in areas with high spatial variability, therefore tracks that sample those areas are expected to produce the most effective corrections, since even small differences in the mesoscale structure and fronts positions can significantly affect the error. In the VOS track network adopted in this work, track 2 samples the West Mediterranean in the Algerian Basin, characterized by a complex meandering current. Track 5 crosses the northwestern Ionian Sea, where in the intermediate and deep layers non-permanent cyclonic structures can be found as well as frontal structures between Adriatic Deep waters and recirculated LIW. Track 7 covers part of the Levantine 

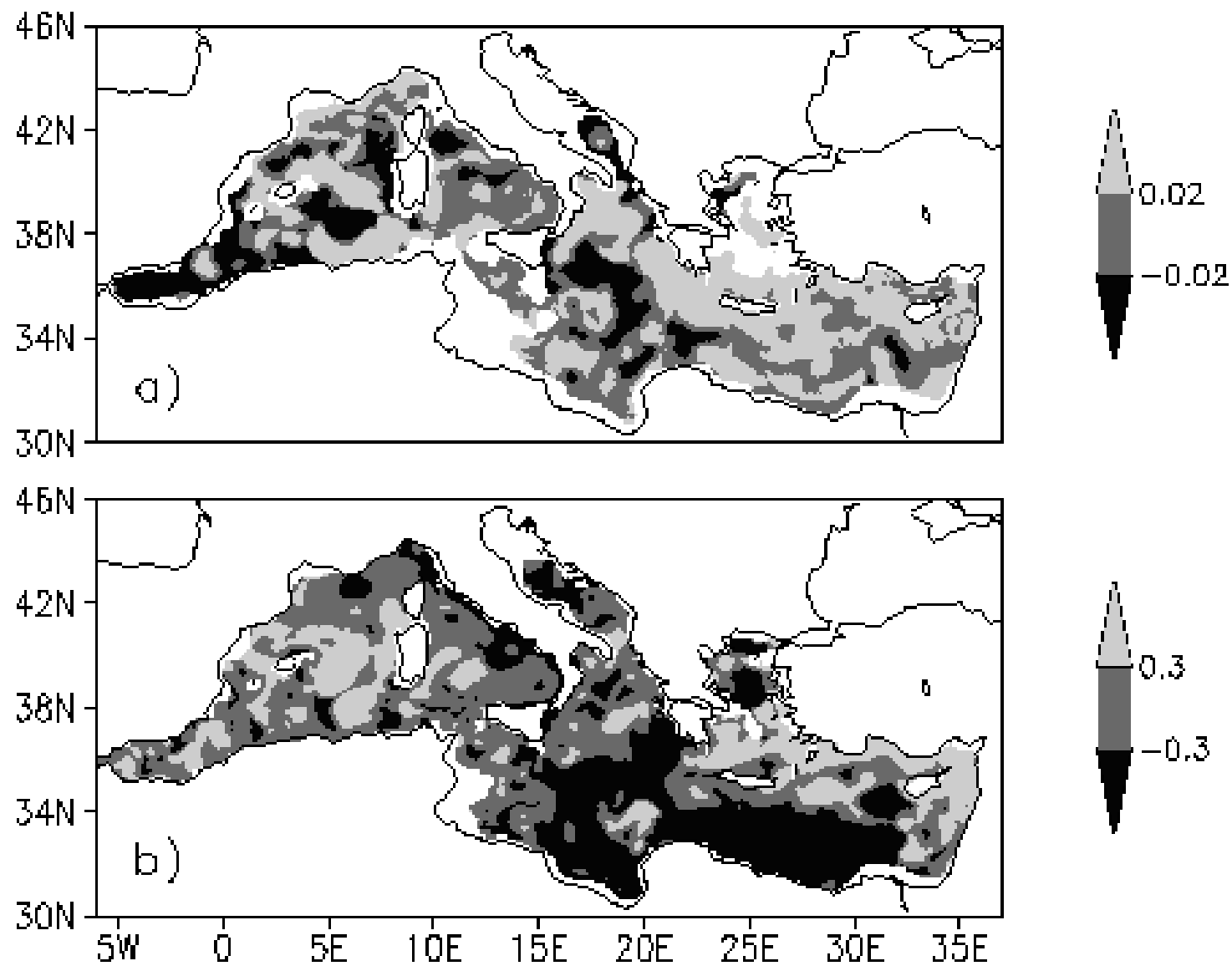

Fig. 10. Differences between the initial conditions of the assimilation and the control runs: (a) summer salinity (psu) at $320 \mathrm{~m}$; (b) winter temperature $\left({ }^{\circ} \mathrm{C}\right)$ at $70 \mathrm{~m}$.

Basin, characterized by the Rhodes, Iérapetra and MersaMatruh gyres (schemes of the main features of the Mediterranean circulation can be found in Malanotte-Rizzoli, 1999; Millot, 1999).

The addition of M3A temperature and salinity data to VOS profiles (strategy IdVOSM3A) generally produce a very small, if not negligible, impact in all seasons and layers. Considering the error reduction achieved by sampling strategy IdVOS as the reference, the improvement with IdVOSM3A is often less than 5\% (generally only $2-3 \%$ ). Figure 11 displays comparisons of relative errors for sampling strategies IdVOSM3A and IdVOS in the cases with the largest impact of the M3A data, namely in winter in the eastern Mediterranean in L2 for temperature (Fig. 11a) and in L1 for salinity (Fig. 11b). The improvement is about 7\% error reduction. The results with M3A data only, namely sampling strategy IdM3A, are also shown.

\section{Assessment of real sampling strategies}

Comparisons of temperature and salinity relative errors using real sampling strategies are shown in Figs. 12-13.

The sampling strategy VtARGO, corresponding to the real data distributions shown in Figs. 5-6, produces temperature relative error reductions up to $30 \%$. The largest impact of temperature data is found in the surface and intermediate layers. More in details, in summer in the West Mediterranean the temperature relative error reduction is up to 20 $25 \%$ (Fig. 12a) while in the eastern basin the maximum is about $10 \%$. In winter in L1 it is about $20 \%$ in the western basin and 30\% in the eastern (Fig. 13a), while in L2 the maximum is about $25 \%$ in both subbasins. In L3 relative the error reduction is generally around 10\% except in the East Mediterranean in summer, where it is almost negligible. Concerning salinity, the relatively small data amount does not allow to reduce the error by more than approximately $10 \%$, as in summer in L1 (Fig. 12b) and in winter in L3, both in the western basin. In most cases the relative error reduction is from negligible to about $5 \%$. Clearly, with strategy VtARGO temperature is corrected more effectively than 


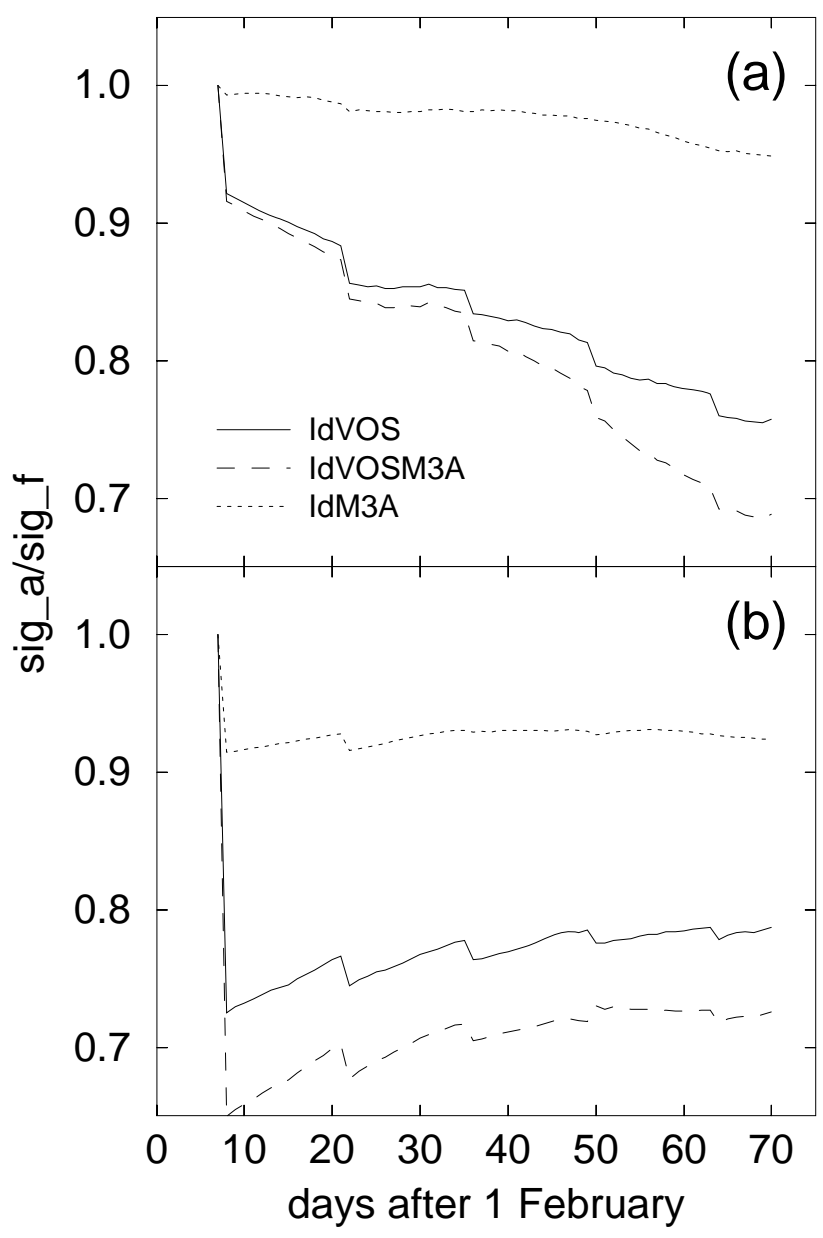

Fig. 11. Time series of relative errors for the East Mediterranean in the winter OSSEs involving M3A data: (a) Salinity in the surface layer, (b) temperature in the intermediate layer.

salinity since the latter is provided by ARGO floats only. The data amount, reported in Table 2, represents a critical factor. The difference is smaller in L3, which is covered by observations only in the upper part (440-775 m).

The addition of salinity data, i.e. the use of sampling strategy VtsARGO, significantly reduces salinity errors (as could be expected). The largest improvement is found in the West Mediterranean in summer, where the error reduction reaches $30 \%$ in L1, namely $20 \%$ further error reduction relative to strategy VtARGO, and $20 \%$ in L2, namely $15 \%$ additional error reduction (Fig. 12b). More limited improvement, but still relatively large, is found in winter, again in the western basin, where the relative error reduction reaches $10 \%$ in L1 and L2. Concerning temperature, a 2-3\% relative error reduction decrease relative to startegy VtARGO is found in summer in the western basin (Fig. 12a), while the differences are small in the other cases.

A major result is that the real sampling strategy VtARGO can achieve error reductions that are comparable to those obtained with the idealized strategy IdVOS. This occurs in the western basin both in summer and winter and only in winter in the eastern basin. Note that in weeks 1-6 the summer data coverage in the East Mediterranean is quite poor (Fig. 5). The comparison is more proper for temperature, while the distributions of salinity data differ significantly between the two sampling strategies. The availability of more salinity profiles is very advantageous to the model performance. In fact, the explicit assimilation of salinity profiles along VOS tracks produces a large decrease of salinity relative errors, together with a marginal improvement to temperature.

The impact of sampling strategy ARGO, consisting of ARGO profiles only, is small in most cases, but, particularly in the deep layer, it is sometimes comparable to that of VOS data. Note, however, that the deep layer is sampled by VOS and ARGO profiles only above approximately $700 \mathrm{~m}$ depth. Its largest effectiveness is found for temperature, in winter in the eastern basin with about $15 \%$ relative error reduction in $\mathrm{L} 1$ and $10 \%$ in L2 (not shown), and in summer in the western basin in L2 and L3, with about $10 \%$ relative error reduction at the end of the run (Fig. 12a). In all other cases the error reduction is almost negligible.

Due to the logistic limitations in the VOS network coverage, ARGO profilers turn out to be the only data source which is continuously available, representing a sort of "background" observing system for temperature and salinity. Despite the small impact of the available ARGO data set, it allows a certain improvement of the model performance and can be regarded as a useful complement to VOS profiles. As an example, Fig. 14 displays spatial distribution of corrections to temperature and salinity made at $5 \mathrm{~m}$ depth after day 7 , that is the end of the first assimilation cycle, using sampling strategy VtARGO. Since the assimilation is performed in smoother mode, all the data in a 14-day window centred on the end of day 7 are taken into account. Therefore, in Fig. 14 the fields are corrected around the data points shown in panels 1 and 2 of Fig. 5 (summer, corresponding to Fig. 14, panels a, c) and Fig. 6 (winter, corresponding to Fig. 14, panels b, d).

Note that relative errors can exhibit increments when corrections are applied, as for summer salinity in the western basin in L2 (Fig. 12b) and winter salinity in the eastern basin in L2 (Fig. 13b). Similar events are also found for summer salinity in the eastern basin in L2, winter salinity in the western basin in L3 and winter temperature in the western basin in L2 and L3 (not shown). The case concerning temperature occurs in week 7 and is related to sampling strategies $\mathrm{Vt}$ and Vts, that include only VOS data. The likely reason is the data lack in the West Mediterranean during weeks $7-8$, while in weeks 1-6 VOS data are available at least every other assimilation cycle (Fig. 6). The cases concerning salinity are observed below the surface layer in both the eastern and western basins and are related to sampling strategies VtARGO and Vt. Changes in the data amount do not seem to be the main reason (see Figs. 5-6), but note that in the above mentioned sampling strategies most of the profiles (VtARGO) or all of 

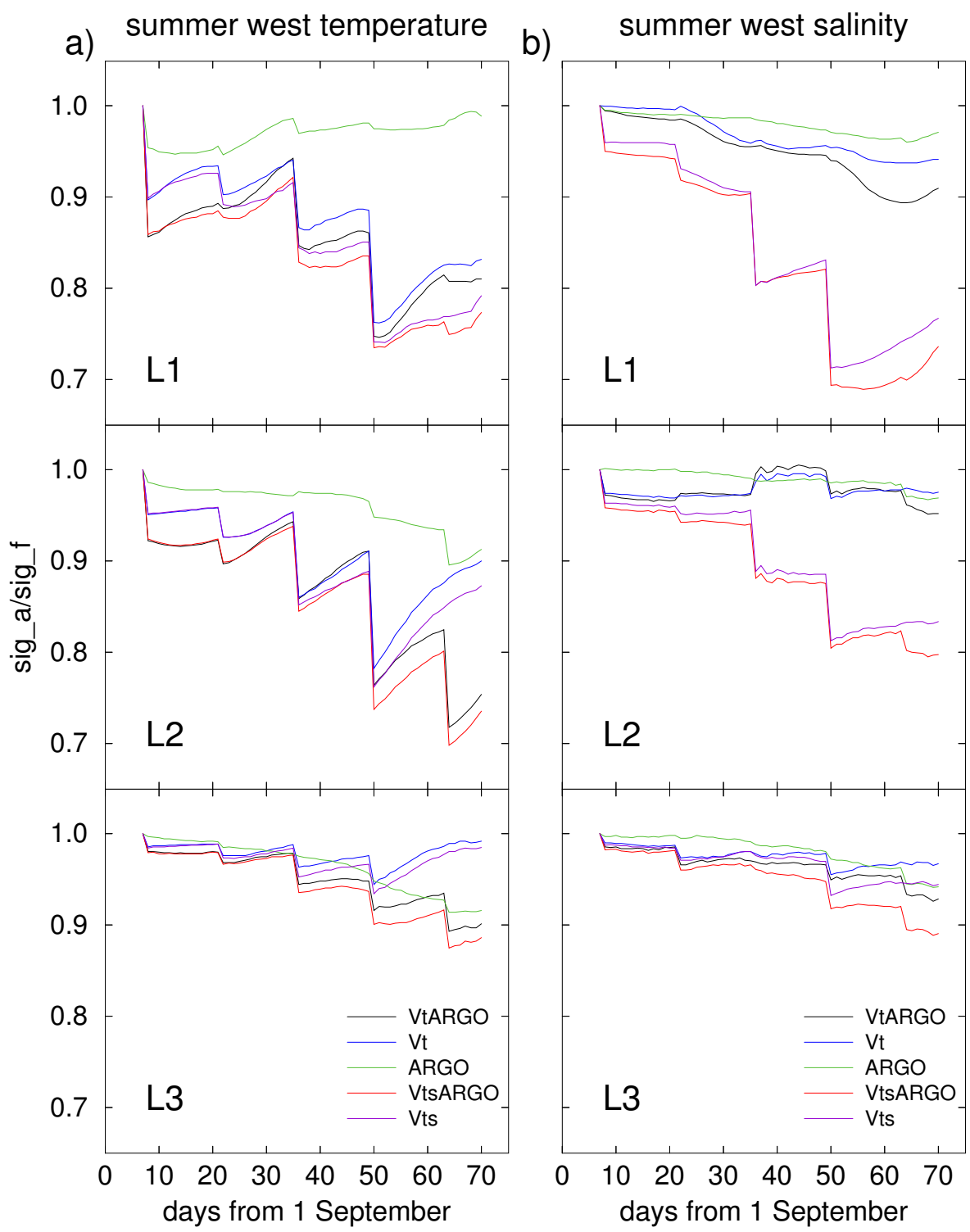

Fig. 12. Time series of temperature (a) and salinity (b) relative errors for the West Mediterranean in the summer OSSEs for real sampling strategies. L1 indicates the surface layer, L2 the intermediate layer and L3 the deep layer.

them (Vt) do not contain salinity data, which is reconstructed from temperature using the bivariate EOFs. As explained in Sect. 2, the EOFs are the result of a statistical analysis of a 1993-1999 model run and may not represent well enough the experimental conditions of summer-autumn 1999 and winter 2000. As a consequence, the salinity reconstruction may not be adequate.

The use of Glider profiles does not represent a significant improvement. Compared to VtARGO, strategy VtARGOG determines an additional relative error reduction which is never greater than 3\%, and in winter in L2 and L3 there is even a small relative error reduction loss, i.e. a worse result. Note, however, that Glider data are available only during weeks 5-10 in summer and 1-4 in winter (Table 2).

\section{Summary and conclusions}

OSSEs have been performed to study and compare the usefulness of different temperature and salinity sampling strategies which are or may be included in the operational observing system set up in the Mediterranean Sea for forecasting purposes. The sampling strategy assessment has been made by means of twin experiments in which the impact of data assimilation into a Mediterranean GCM is quantified as the error reduction achieved in the assimilation run relative to the free run.

The impact of temperature and salinity profiles along VOS tracks has been studied in idealized configurations. The importance of each track has been assessed in terms of relative 

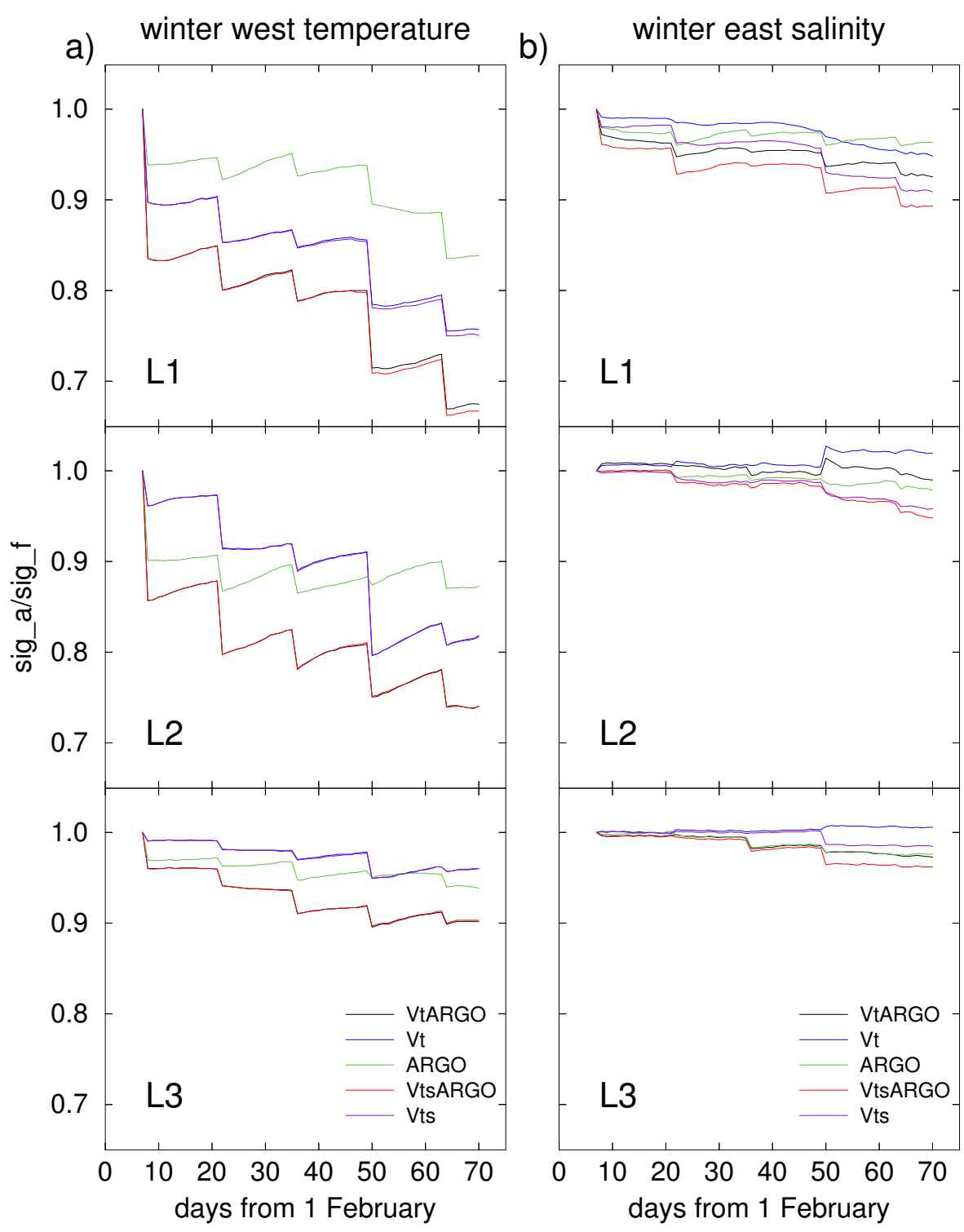

Fig. 13. Time series of temperature (a) and salinity (b) relative errors for the East Mediterranean in the winter OSSEs for real sampling strategies. L1 indicates the surface layer, L2 the intermediate layer and L3 the deep layer.

error reduction loss when it is removed from the whole data set. As a result, the largest impact is associated to tracks crossing regions with complex dynamics, namely track 2 , that crosses the Algerian Current, and track 5, crossing the northwestern Ionian Sea and the steep escarpment to the East of Sicily. Such regions are characterized by mesoscale variability and frontal structures that exhibit notable interannual variability.

A major result of the real sampling strategy assessment is that the temperature profiles from VOS and temperature and salinity profiles from ARGO floats, that have been actually obtained in summer autumn 2004 and winter 2005, can produce error reductions that are comparable to those obtained with the idealized strategy IdVOS. The direct availability of salinity data along VOS tracks, together with temperature, would greatly improve the model performance, since the salinity reconstructed using EOFs seems in some cases inadequate. The impact of ARGO data is generally small, but sometimes comparable to that of VOS data. The combination of VOS and ARGO seems to be the most useful solution, since the VOS programme, whose flexibility is limited by several practical constraints, can be complemented by the ARGO floats, that, although in a limited number, represent a continuously available data source scattered over a wide area.

Localized data as the M3A profiles, in the idealized sampling strategies, and Glider profiles, in the real case, turn out to be of little usefulness in comparison to data sets that cover wide areas. It should be reminded that the present analysis 

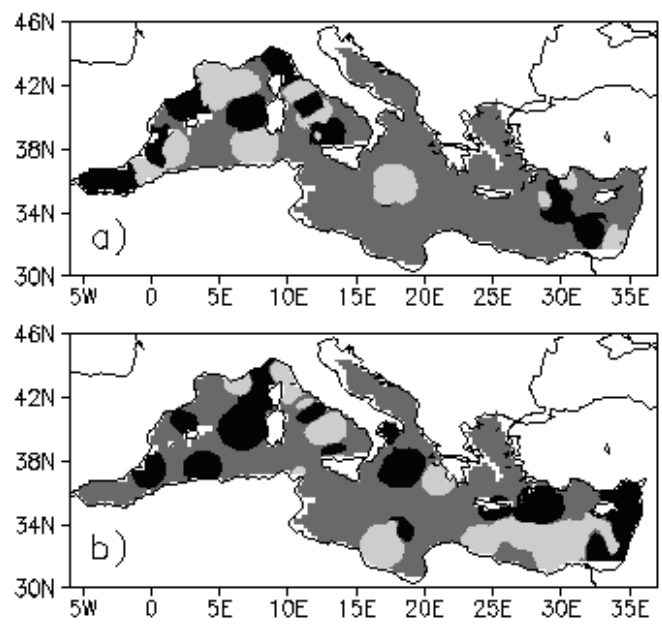
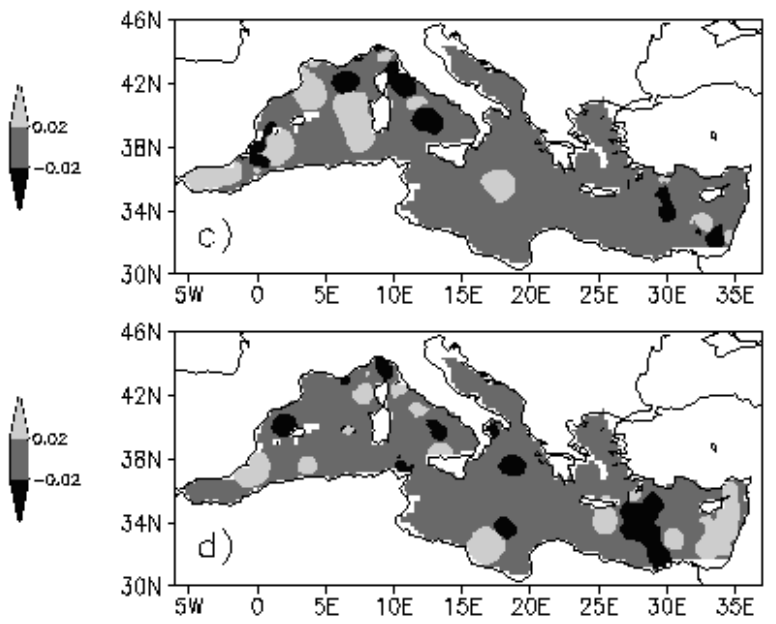
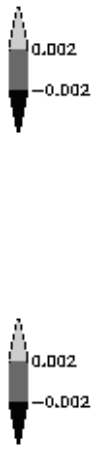

Fig. 14. Maps of corrections at $5 \mathrm{~m}$ depth after the first assimilation cycle (day 7) with sampling strategy VtARGO. Left panels: temperature $\left({ }^{\circ} \mathrm{C}\right)$ in summer (a) and winter (b). Right panels: salinity (psu) in summer (c) and winter (d).

is performed at large scale, namely for the East and West Mediterranean basins, and the impact of localized data set is certainly much more significant at a regional scale, particularly in the absence of other data sources. Although the idealized M3A network covers the whole Mediterranean, its impact is still almost negligible at a basin scale.

It should be remarked that the approach followed in this work exhibits some limitations, among which: a) The twin experiments are designed and analysed in order to assess the impact of data that simulate near-real time observations used for assimilation for forecasting purposes. Different objectives, like, for instance, routine monitoring, may not benefit from the assessment performed in this work and may require different approaches. b) The OSSE results depend on the model used to perform the simulations. As an example, the $1 / 8^{\circ}$ Mediterranean GCM used here cannot reproduce small, but highly energetic structures that may be critical in certain areas. c) The synthetic data used in the OSSEs are extracted from the model itself, thus being fully consistent with it. This may result in an optimistic assessment with respect to the use of real data. d) Data error covariance is kept constant instead of being variable in space and time.

The OSSEs described here and in Raicich and Rampazzo (2003) represent the first experience of this kind in the Mediterranean Sea. They have been performed using data assimilation based on optimal interpolation because that was the choice for the operational forecasting system. As a future perspective, the application of other methodologies for data assimilation, such as, for instance, those based on variational or ensemble techniques, may help to overcome some limitations of the present work.

Acknowledgements. The Author would like to thank M. Adani (INGV, Bologna) for providing the bivariate TS EOFs and S. Sparnocchia (CNR-ISMAR, Trieste) for fruitful discussion.
The positions and times of real data used in this work are made freely available by the French Coriolis project and the International Argo Project through the Coriolis Data Centre (http://www.coriolis. eu.org).

This work has been partly supported by the "Mediterranean ocean Forecasting System Towards Environmental Prediction" project, EC Contract EVK3-CT2002-00075.

Edited by: N. Pinardi

\section{References}

Arnold Jr., C. P. and Dey, C. H.: Observing-system simulation experiments: Past, present and future, Bull. Am. Meteor. Soc., 67, 687-695, 1986.

Barth, N. and Wunsch, C.: Oceanographic experiment design by simulated annealing, J. Phys. Oceanogr., 20, 1249-1263, 1990.

Bennett, A. F.: Inverse methods for assessing ship-of-opportunity networks and estimating circulation and winds from tropical expendable bathythermograph data, J. Geophys. Res., 95, $16111-$ $16148,1990$.

Brankart, J.-M. and Pinardi, N.: Abrupt cooling of the Mediterranean Levantine Intermediate Water at the beginning of the eighties: observational evidence and model simulation, J. Phys. Oceanogr., 31, 2307-2320, 2001.

Brasseur, P., Beckers, J.-M., Brankart, J.-M., and Schoenauen, R.: Seasonal temperature and salinity fields in the Mediterranean Sea: Climatological analyses of an historical data set, Deep-Sea Res., 43, 159-192, 1996.

Castellari, S., Pinardi, N., and Leaman, K.: A model study of air-sea interactions in the Mediterranean Sea, J. Mar. Syst., 18, 89-114, 1998.

Castellari, S., Pinardi, N., and Leaman, K.: Simulation of water mass formation processes in the Mediterranean Sea: influence of the time frequency of the atmospheric forcing, J. Geophys. Res., 105, 24 157-24 181, 2000. 
De Mey, P.: Optimal interpolation in a model of the Azores current in 1986-88, in: Data assimilation: Tools for modelling the ocean in a global perspective, NATO/ASI Series, I/19, edited by: Brasseur, P. P. and Nihoul, J. C. J., Springer-Verlag, 253 pp, 1994.

De Mey, P.: Data assimilation at the oceanic mesoscale: A Review, J. Meteorol. Soc. Japan, 75, Special issue on "Data assimilation in meteorology and oceanography: Theory and practice", 415427, 1997.

De Mey, P. and Benkiran, M.: A multivariate reduced-order optimal interpolation method and its application to the Mediterranean basin-scale circulation, in: Ocean Forecasting Conceptual Basis and Applications, edited by: Pinardi, N. and Woods, J., Springer-Verlag, 281-306, 2002.

Demirov, E. and Pinardi, N.: Simulation of the Mediterranean Sea circulation from 1979 to 1993: Part I. The interannual variability, J. Mar. Syst., 33-34, 23-50, 2002.

Demirov, E., Pinardi, N., Fratianni, C., Tonani, M., Giacomelli, L., and De Mey, P.: Assimilation scheme of Mediterranean Forecasting System: Operational implementation, Ann. Geophys., 21, 189-204, 2003, http://www.ann-geophys.net/21/189/2003/.

Derber, J. and Rosati, A.: A global oceanic data assimilation scheme, J. Phys. Oceanogr., 19, 1333-1347, 1989.

Fichaut, M., Balopoulos, E., Dooley, H., García-Fernandez, M.-J., Iona, A., Jourdan, D., Baudet, L., and Maillard, C.: A common protocol to assemble a coherent database from distributed heterogeneous data sets: The MEDATLAS database experience, in: Marine science and technology programme: Experiences in project data management, edited by: Bohle-Carbonell, M., European Commission, Luxembourg, 349 pp, 1998.

Griffa, A., Molcard, A., Raicich, F., and Rupolo, V.: Assessment of the impact of TS assimilation from ARGO floats in the Mediterranean Sea, Ocean Sci. Discuss., 3, 671-700, 2006, http://www.ocean-sci-discuss.net/3/671/2006/.

Guinehut, S., Larnicol, G., and Le Traon, P.-Y.: Design of an array of profiling floats in the North Atlantic from model simulations, J. Mar. Syst., 35, 1-9, 2002.

Guinehut, S., Le Traon, P.-Y., Larnicol, G., and Philipps, S.: Combining Argo and remote-sensing data to estimate the ocean threedimensional temperature fields - A first approach based on simulated observations, J. Mar. Syst., 46, 85-98, 2004.

Hackert, E. C., Miller, R. N., and Busalacchi, A. J.: An optimized design for a moored instrument array in the tropical Atlantic Ocean, J. Geophys. Res., 103, 7491-7509, 1998.

Hernandez, F., Le Traon, P.-Y., and Barth, N. H.: Optimizing a drifter cast strategy with a genetic algorithm, J. Atmos. Ocean. Tech., 12, 330-345, 1994.

Kindle, J. C.: Sampling strategies and model assimilation of altimetric data for ocean monitoring and prediction, J. Geophys. Res., 91, 2418-2432, 1986.

Korres, G., Pinardi, N., and Lascaratos, A.: The ocean response to low-frequency interannual atmospheric variability in the Mediterranean Sea. Part I: sensitivity experiments and energy analysis, J. Climate, 13, 705-731, 2000.
LeTraon, P.-Y. and Ogor, F.: ERS-1/2 orbit improvement using Topex/Poseidon: the $2 \mathrm{~cm}$ challenge, J. Geophys. Res., 103, 8045-8050, 1998.

Malanotte-Rizzoli, P., Manca, B. B., Ribera d'Alcalà, M., Theocharis, A., Brenner, S., Budillon, G., and Özsöy, E.: The Eastern Mediterranean in the 80s and in the 90s: the big transition in the intermediate and deep circulations, Dyn. Atmos. Oceans, 29, 365-395, 1999.

Manzella, G. M. R., Scoccimarro, E., Pinardi, N., and Tonani, M.: Improved near-real time management procedures for the Mediterranean ocean Forecasting System - Voluntary Observing Ship program, Ann. Geophys., 21, 49-62, 2003, http://www.ann-geophys.net/21/49/2003/.

Millot, C.: Circulation in the Western Mediterranean Sea, J. Mar. Syst., 20, 423-442, 1999.

Miyakoda, K., Smagorinsky, J., Strickler, R. F., and Hembree, G. D.: Experimental extended predictions with a nine-level hemispheric model, Mon. Wea. Rev., 97, 1-76, 1969.

Nittis, K., Tziavos, C., Thanos, I., Drakopoulos, P., Cardin, V., Gačić, M., Petihakis, G., and Basana, R.: The Mediterranean Moored Multi-sensor Array (M3A): system development and initial results, Ann. Geophys., 21, 75-87, 2003, http://www.ann-geophys.net/21/75/2003/.

Özsöy, E., Hecht, A., Ünlüata, Ü., Brenner, S., Sur, S., Bishop, H. I., Latif, M. A., Rosentroub, Z., and Oğuz, T.: A synthesis of the Levantine Basin circulation and hydrography, 1985-1990, DeepSea Res., Part II, 40, 1075-1119, 1993.

Pacanowski, R. C., Dixon, K., and Rosati, A.: The GFDL Modular Ocean Model users guide, version 1.0, Geophysical Fluid Dynamics Laboratory Ocean Tech. Rep. 2, 18 pp, 1990.

Poulain, P.-M.: A profiling float program in the Mediterranean, Argonautics, 6, 2, 2005.

Pinardi, N. and Flemming, N. C. (Eds.): The Mediterranean Forecasting System Science Plan, EuroGOOS Publication No. 11, Southampton Oceanographic Centre, Southampton, UK, 52 pp, 1998.

Raicich, F. and Rampazzo, A.: Observing System Simulation Experiments for the assessment of temperature sampling strategies in the Mediterranean Sea, Ann. Geophys., 21, 151-165, 2003, http://www.ann-geophys.net/21/151/2003/.

Rohaly, G. D. and Krishnamurti, I. N.: An observing system simulation experiment for the Laser Atmospheric Wind Sounder (LAWS), J. Appl. Meteorol., 32, 1453-1471, 1993.

She, J., Høyer, J. L., and Larsen, J.: Assessment of sea surface temperature observational networks in the Baltic Sea and North Sea, J. Mar. Syst., Special Issue "Marine Environmental Monitoring and Prediction", in press, 2006.

Sparnocchia, S., Pinardi, N., and Demirov, E.: Multivariate Empirical Orthogonal Function analysis of the upper thermocline structure of the Mediterranean Sea from observations and model simulations, Ann. Geophys., 21, 167-187, 2003, http://www.ann-geophys.net/21/167/2003/.

Taillandier, V., Griffa, A., Poulain, P.-M., and Béranger, K.: Assimilation of Argo float positions in the north western Mediterranean Sea and impact on ocean circulation simulations, Geophys. Res. Lett., 33, L11604, doi:10.1029/2005GL025552, 2006. 